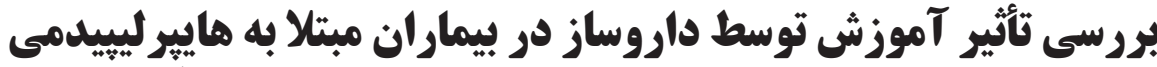

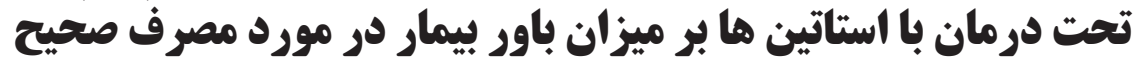 \\ الين دارون فونا
}

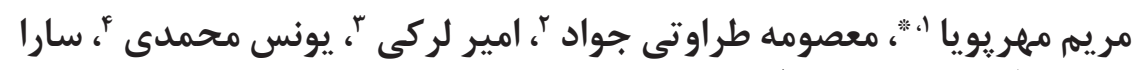

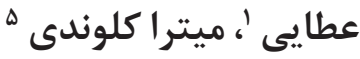

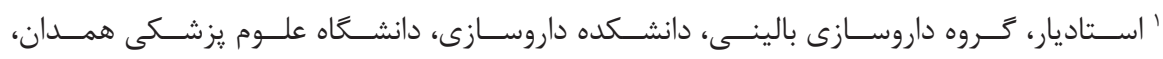

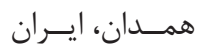

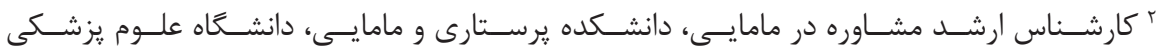

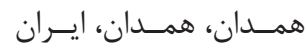

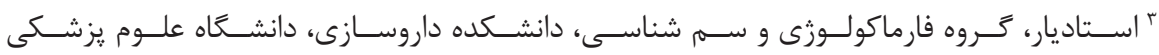

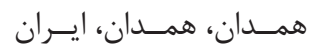

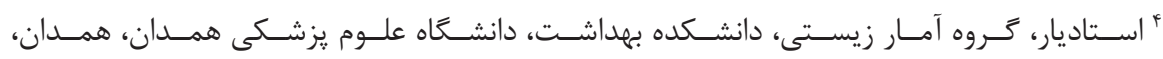
ايسران

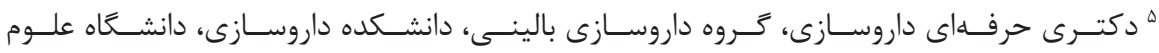

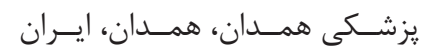

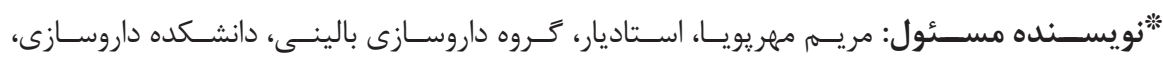

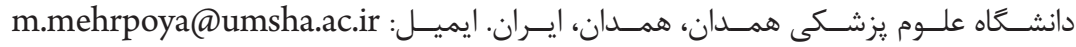

DOI: 10.21859 /hums-24019

جكيده

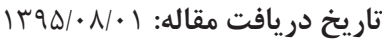

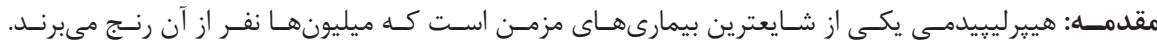

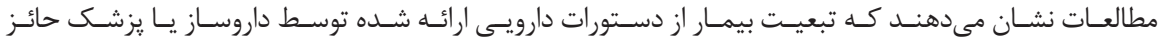

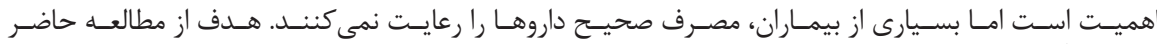

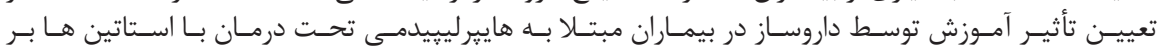

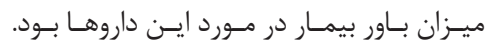

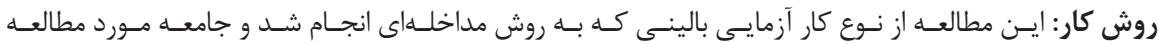

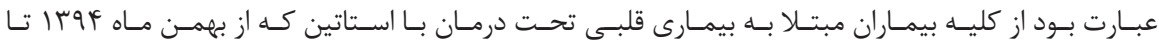

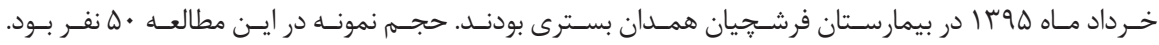

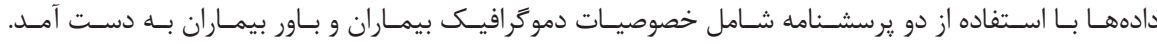

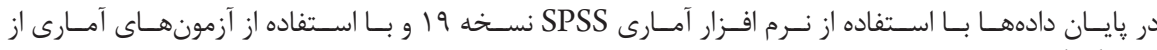
t-test، Mann-Whithney

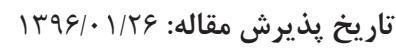

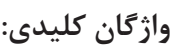
آموزش افزايش خربى خون باور

داروها- استفاده درمانى

تمامى حقوق نشر براى دانشگاه علوم يزشكى همدان محفوظ است.

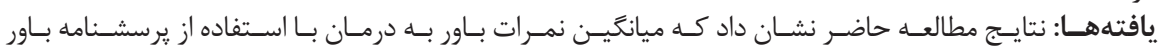

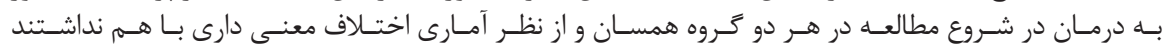

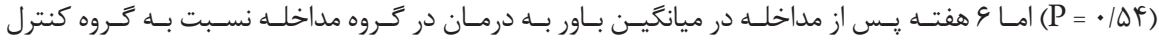

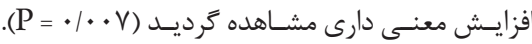

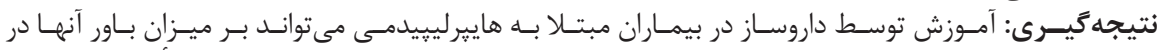

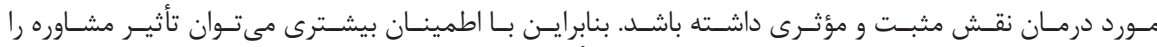

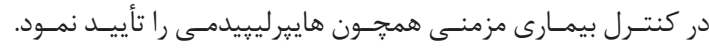

بــه طـور معمـول هييرليِيدمسى از شـيوه نامناسـب زندَّى شـامل

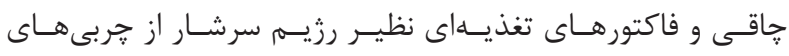

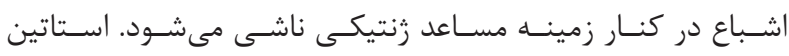

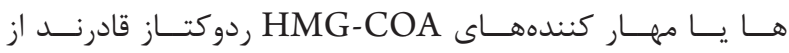

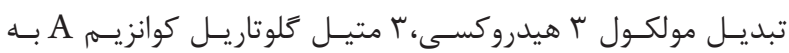

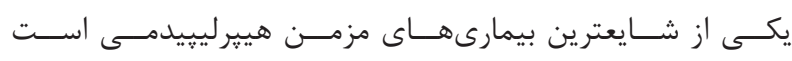

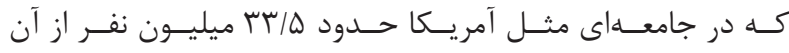

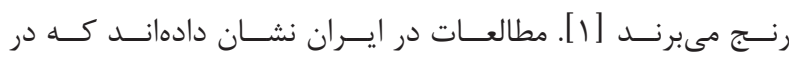

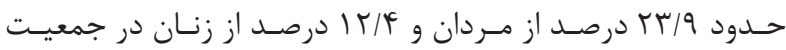

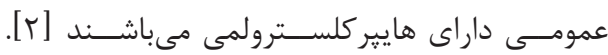




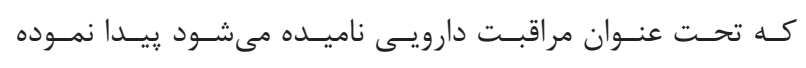

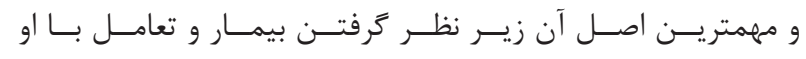

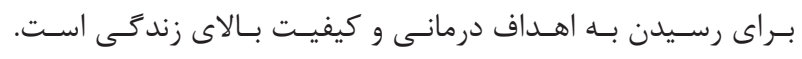

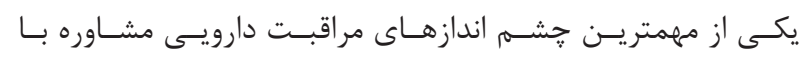

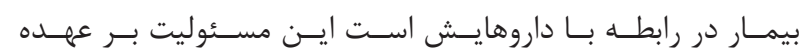

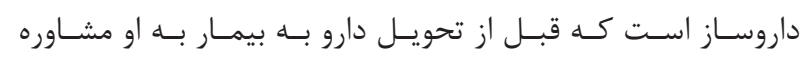

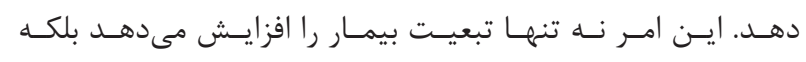

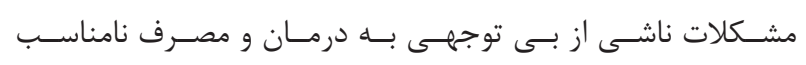

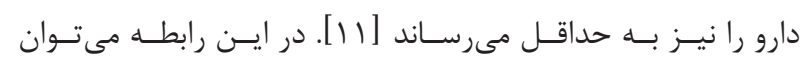

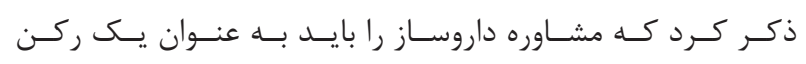

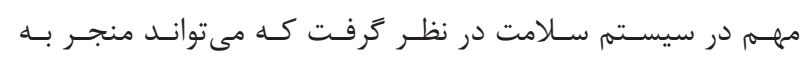

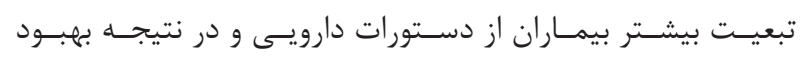

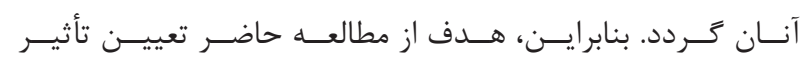

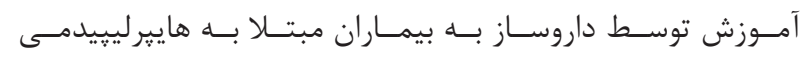

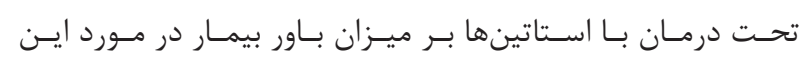
داروهـا بـود.

روش كار

مطالعـه حاضــر از نــوع كار آزمايسى بالينـى تصادفـى شــــه بــود.

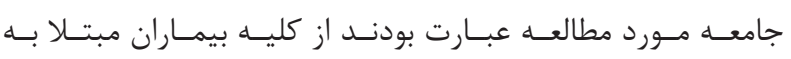

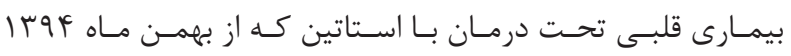

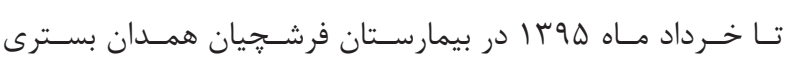

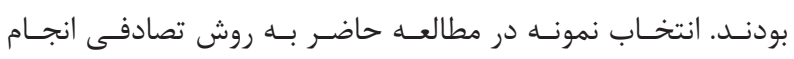

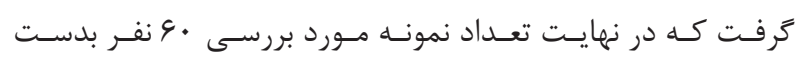

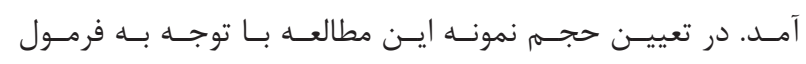

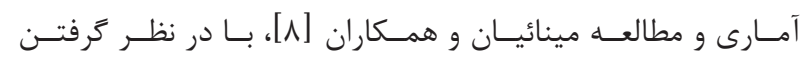

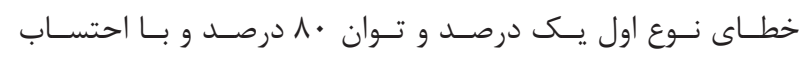

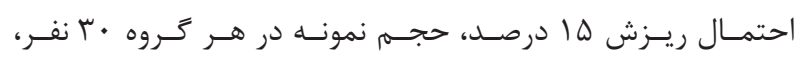

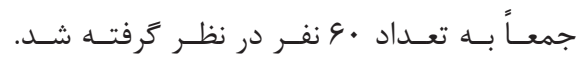

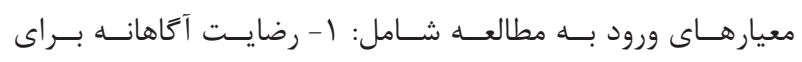

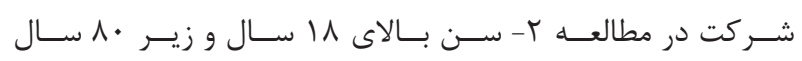

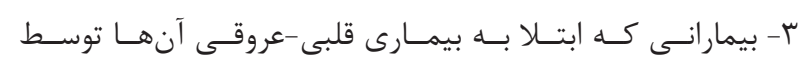

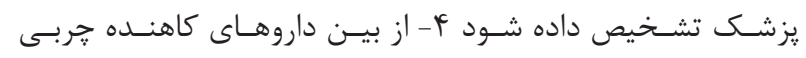

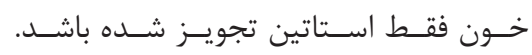

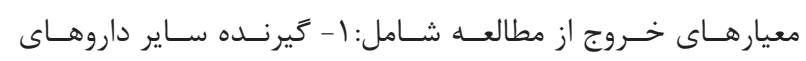

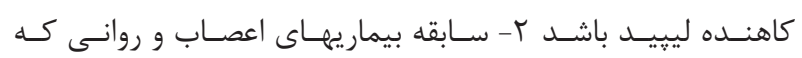

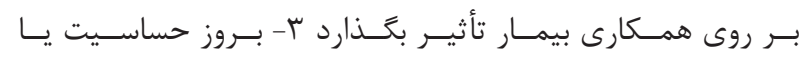

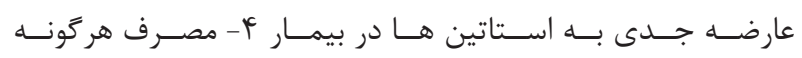

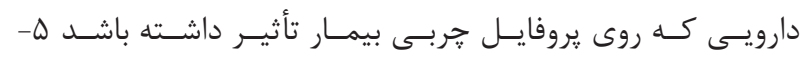

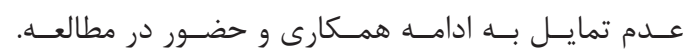

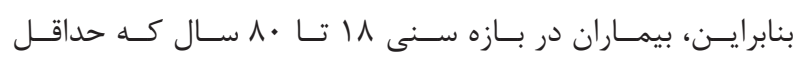

موالونـات كـهـ يكـى از مولكولهــاى بينابينـى در ســنتز كلسـترول

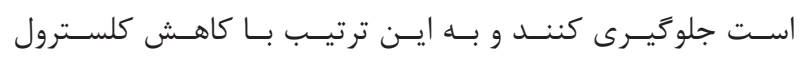

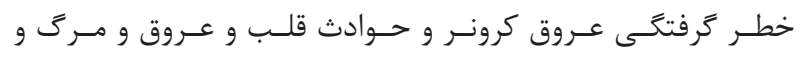

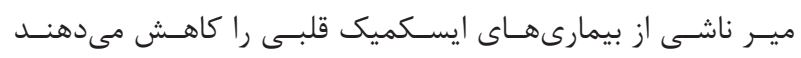

American Heart) بـر اسـاس راهنمــاى انجمـن قلـب آمريــا

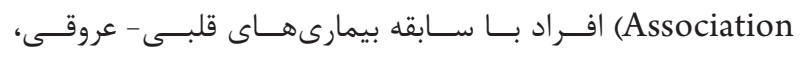

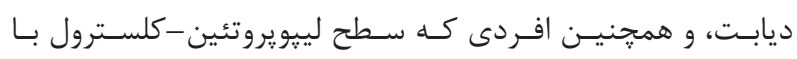

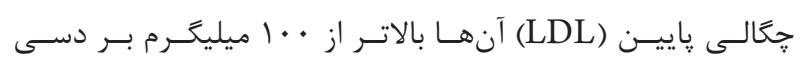

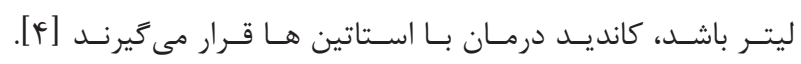

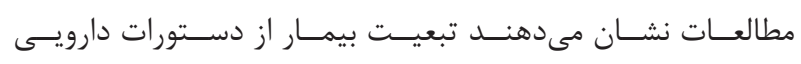

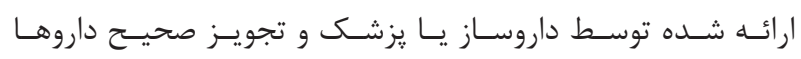

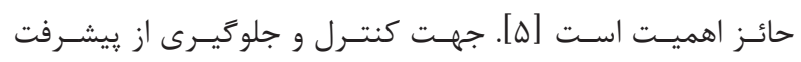

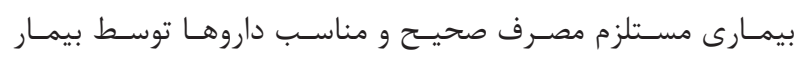

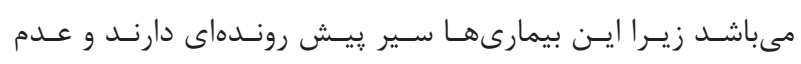

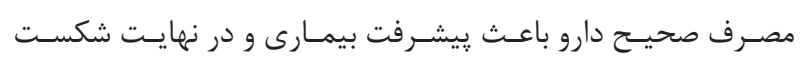

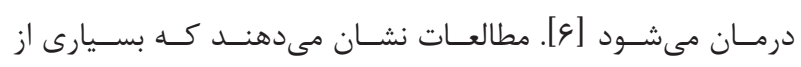

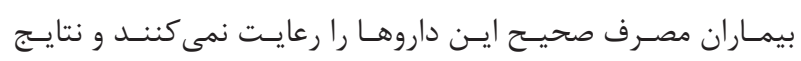

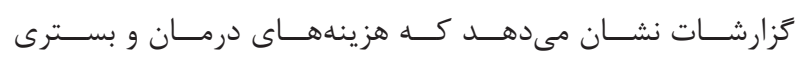

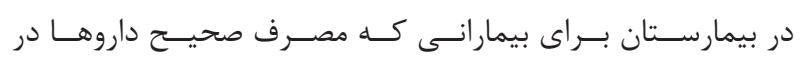

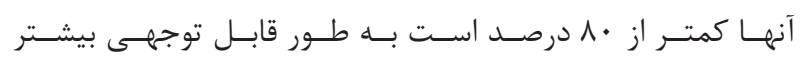

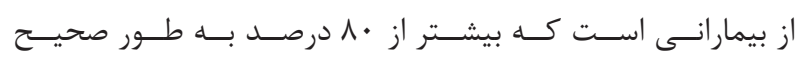

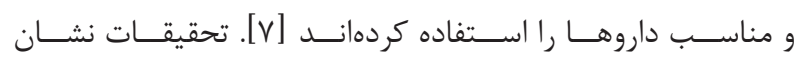

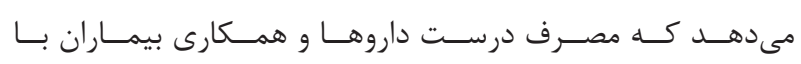

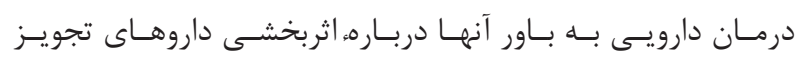

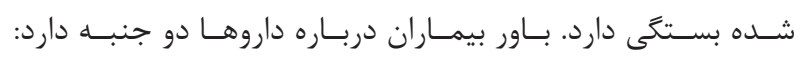

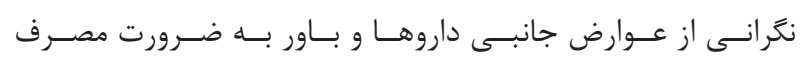

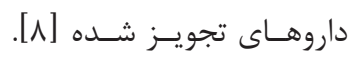

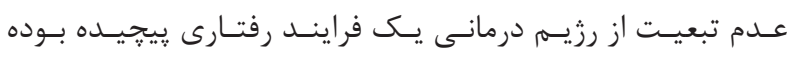

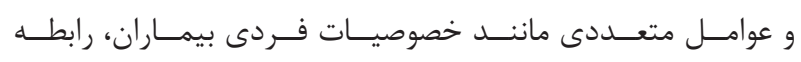

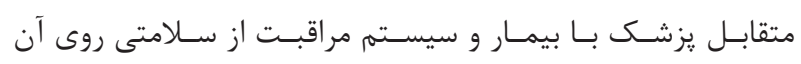

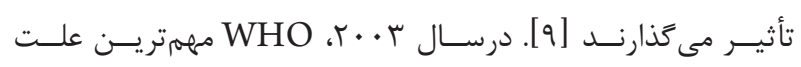

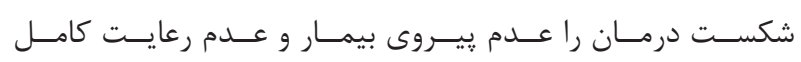

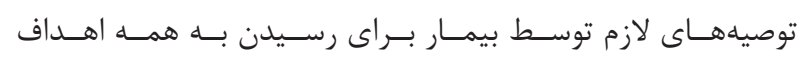
درمانسى اعـلام كـرد [ [1]].

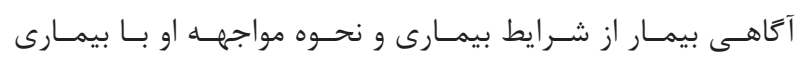

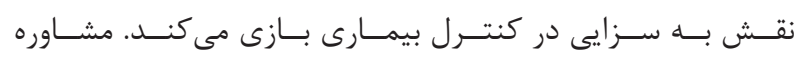

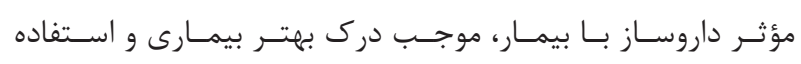

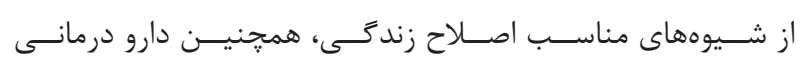

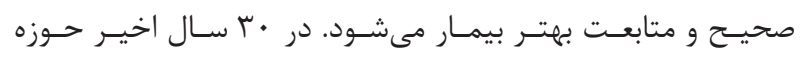

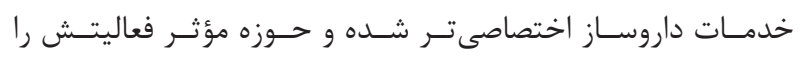




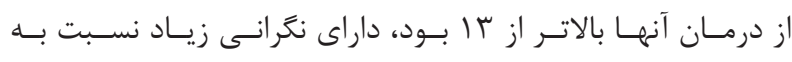

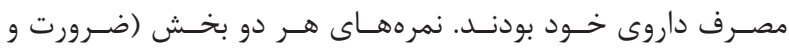

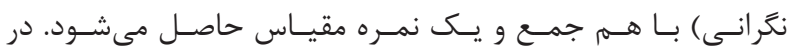

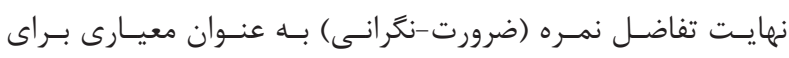

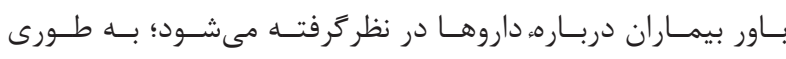

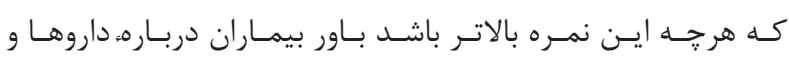

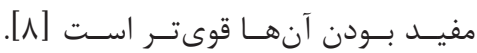

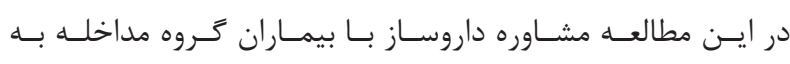

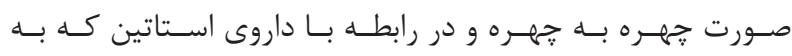

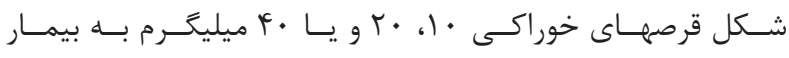

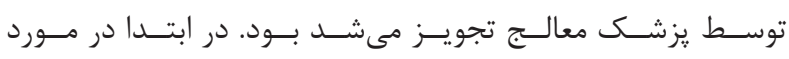

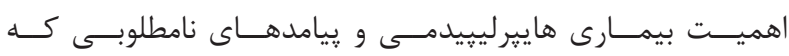

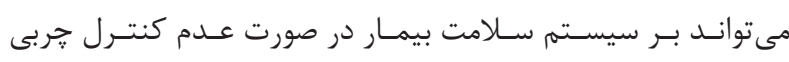

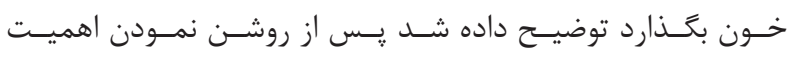

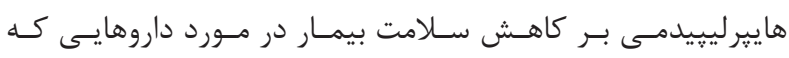

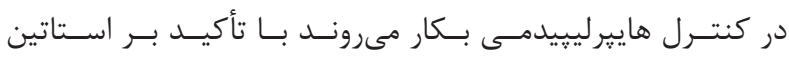

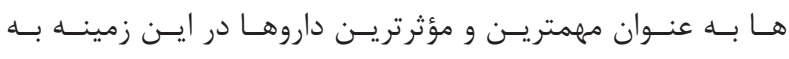

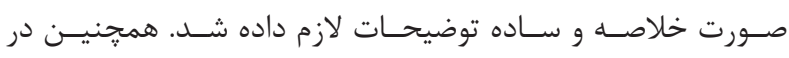

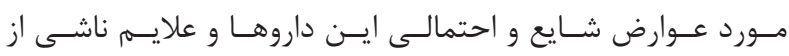

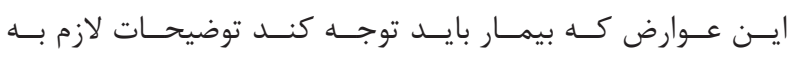

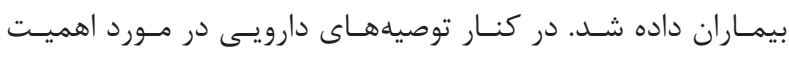

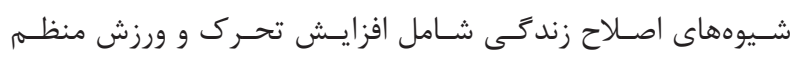

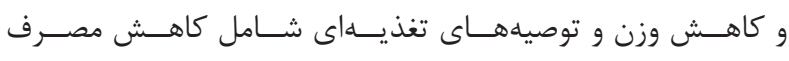

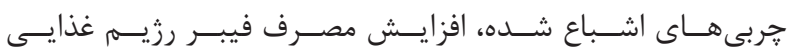

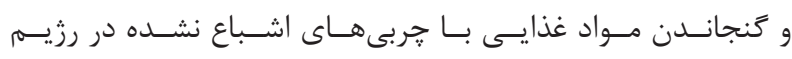

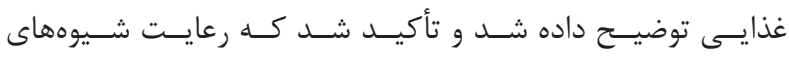

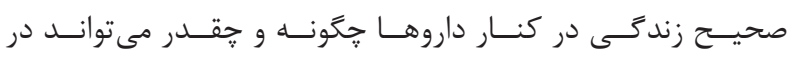

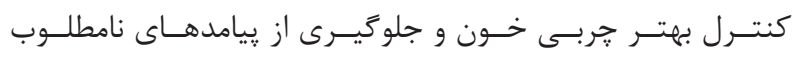

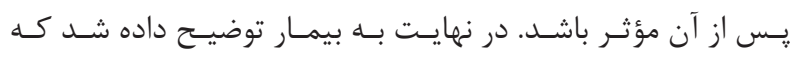

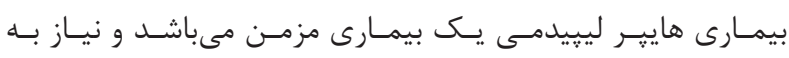

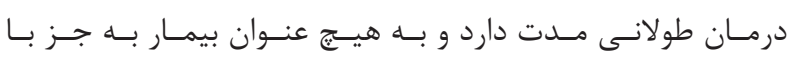

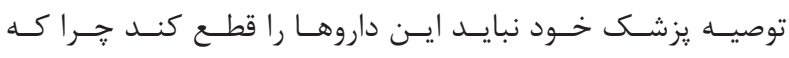

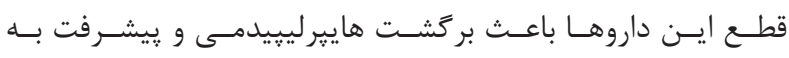

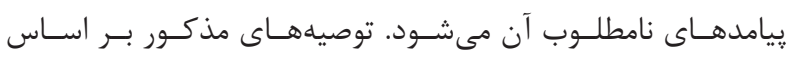

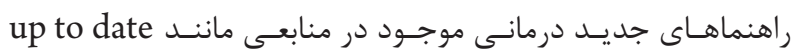

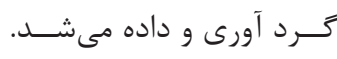

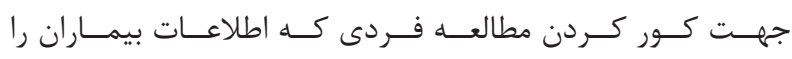

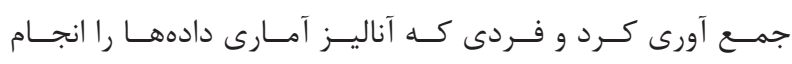

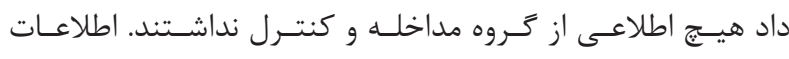

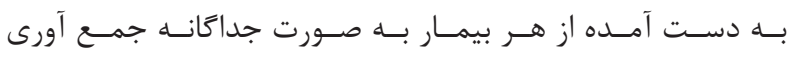

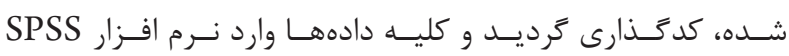

يـك داروى مرتبــط بــا حــروه دارويسى اسـتاتينها را بـهـ مــدت

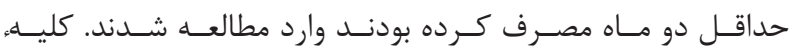

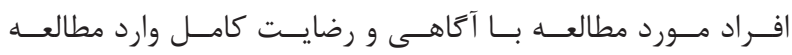

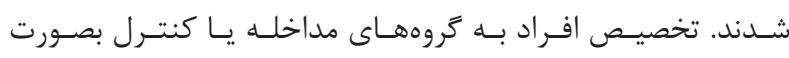

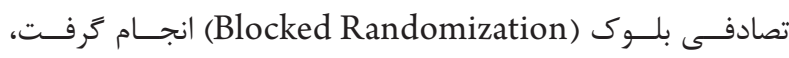

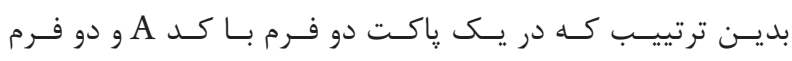

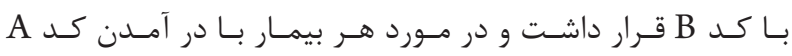

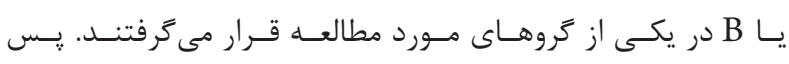

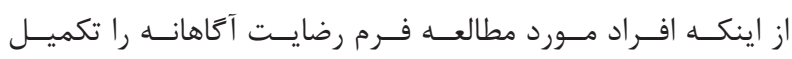

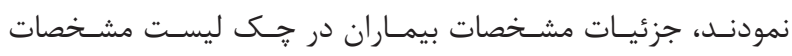

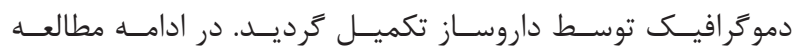

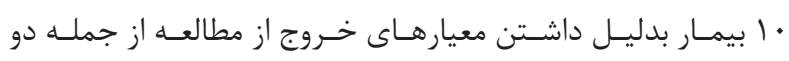

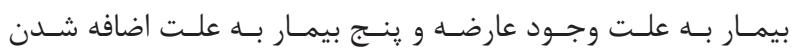

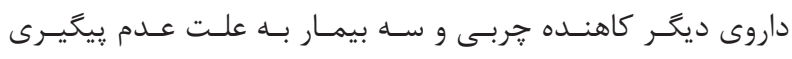

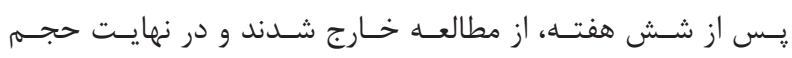

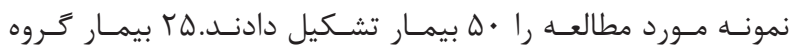

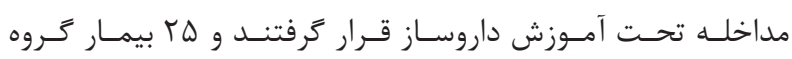

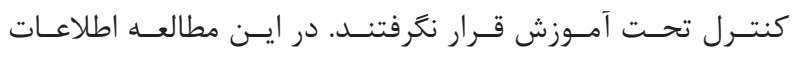

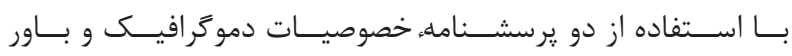
بيماران (BMQ Beliefs about medicines questionnaire)

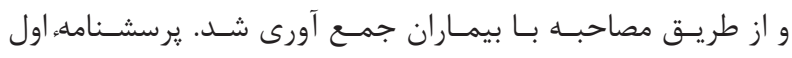

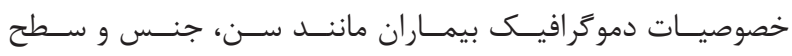

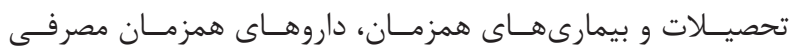

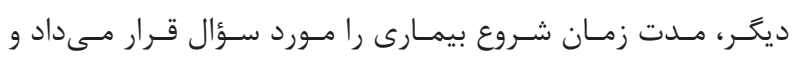

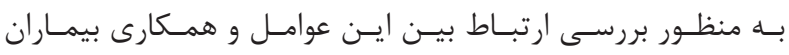

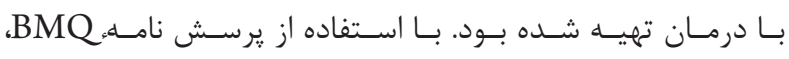

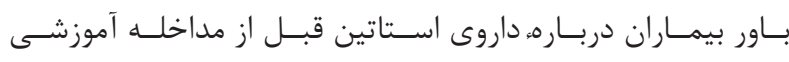

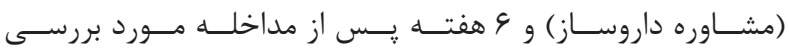

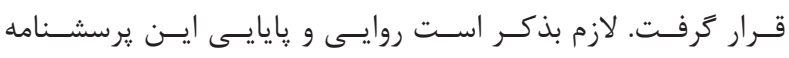

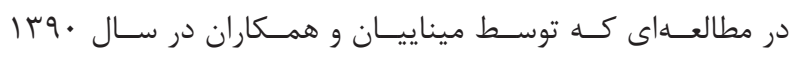

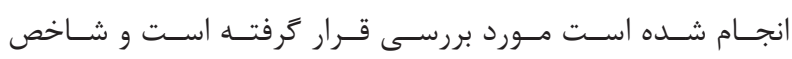

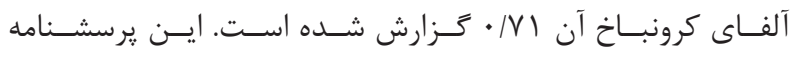

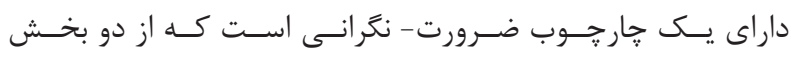

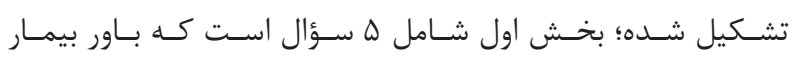

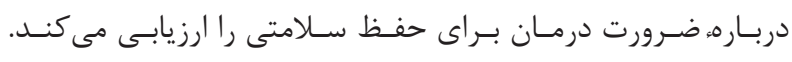

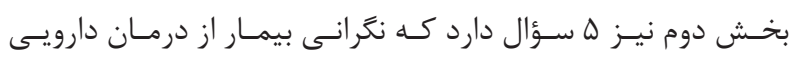

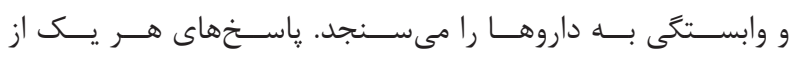

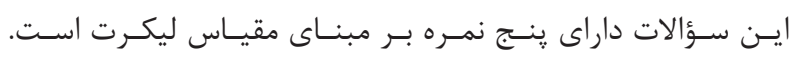

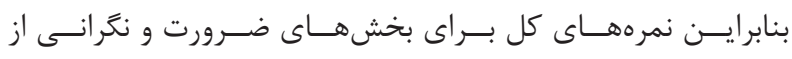

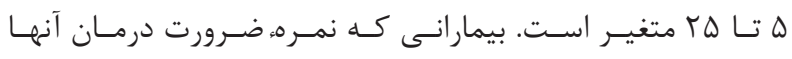

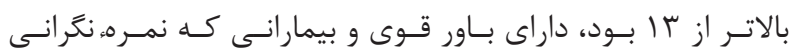




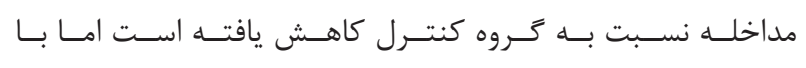

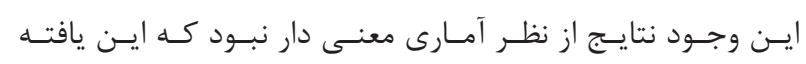

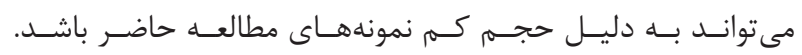

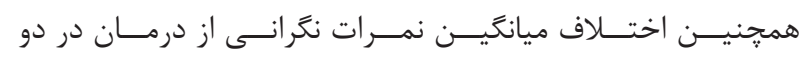

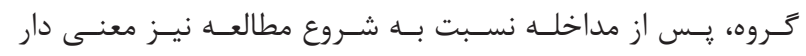

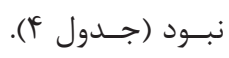

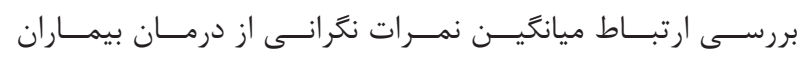

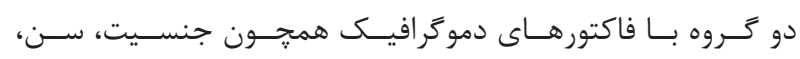

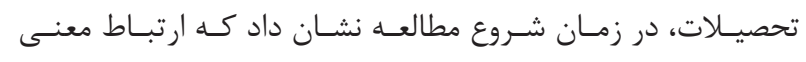

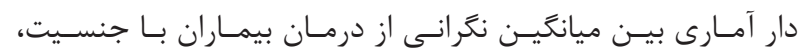

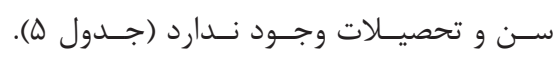

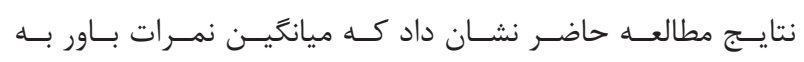

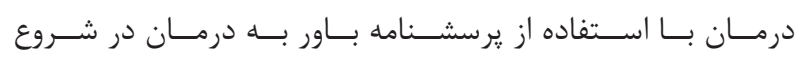

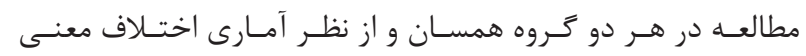

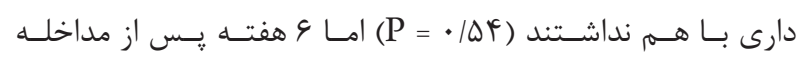

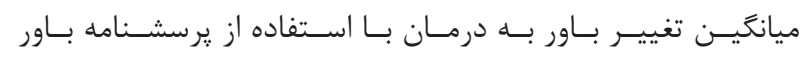

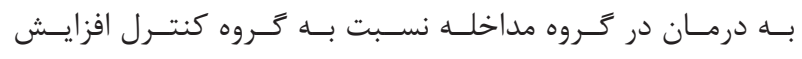

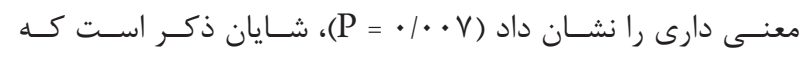

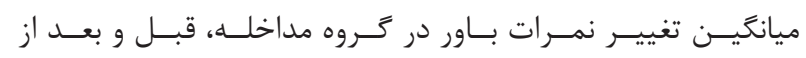

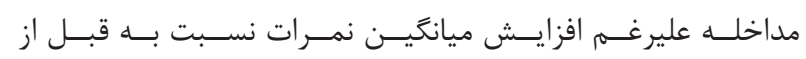

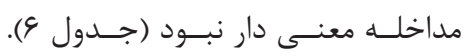

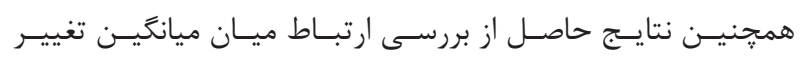

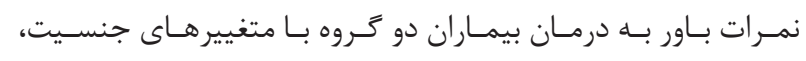

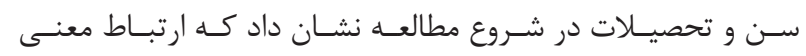

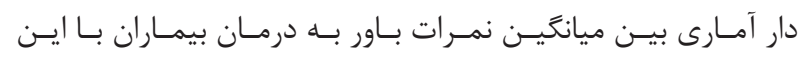

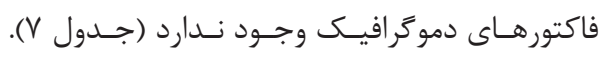

نسـخه 9 ا شــــ بـراى تجزيـهـ و تحليـل دادههـاى بـا توزيـع نرمـال

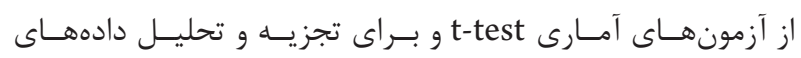

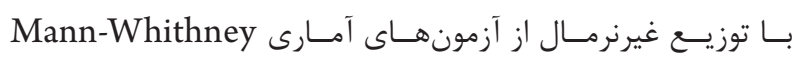

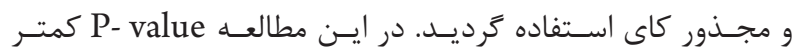

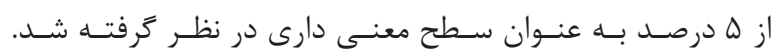

\section{افافته ها}

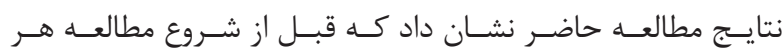

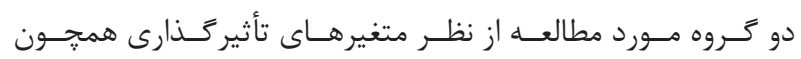

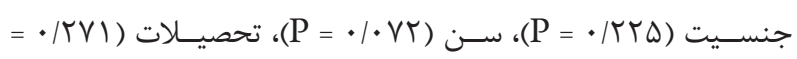

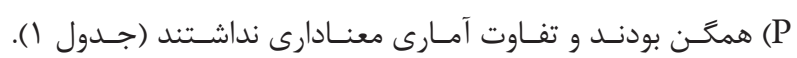

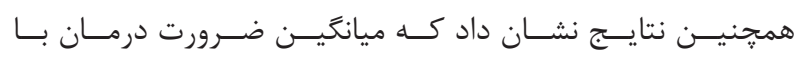

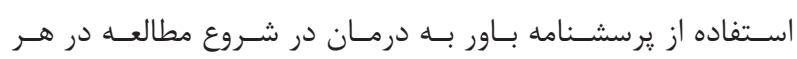

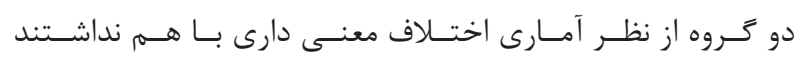

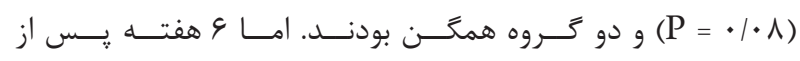

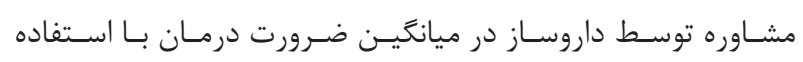

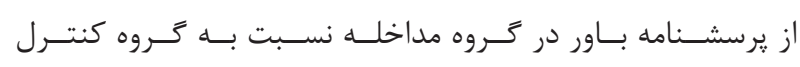

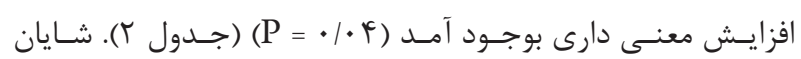

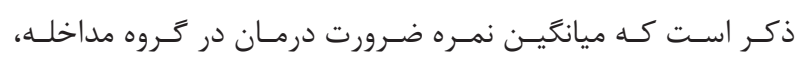

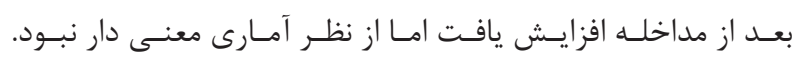

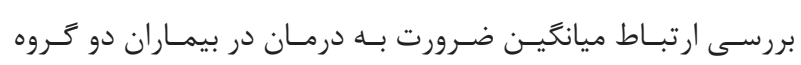

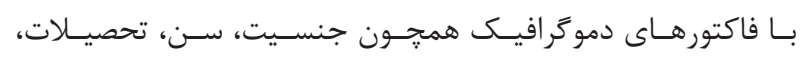

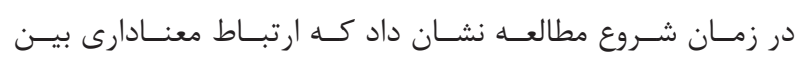

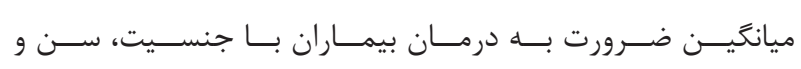
تحصيـلات وجـود نــدارد (جــدول بان).

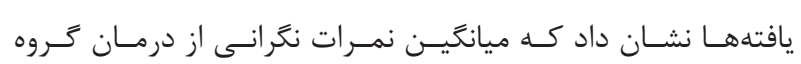

\begin{tabular}{|c|c|c|c|}
\hline \multicolumn{4}{|c|}{ جدول ا: توزيع متغيرهاى دموگرافيك بيماران در شروع مطالعه در هر دو كروه } \\
\hline ارزش & 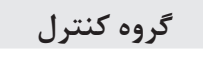 & كَروه مداخله & متغيير \\
\hline$\cdot / \cdot \vee$ & $k q / q \uparrow \pm 1 \cdot 1 \cdots$ & $\Delta r / V T \pm Y / \Lambda$ & سن، ميانغين土 انحراف معيار \\
\hline 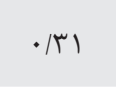 & $r / V T \pm T / \mathcal{E}$ & $r / \mathcal{\Psi} \pm r / \uparrow \varphi$ & طحرل مدت بيمارى، ميانغيند \\
\hline \multirow[t]{3}{*}{$\cdot / 4 t$} & & & جنسيت \\
\hline & $(Y Y / \cdot \cdot) \varphi$ & $(1 \cdot / \cdots))$ & مرد \\
\hline & $(\vee 9 / \cdots) 19$ & $(9 \cdot 1 \cdot \cdot) 10$ & 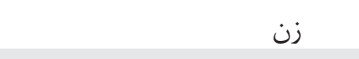 \\
\hline \multirow[t]{4}{*}{$\cdot / 4 V$} & & & تحصيلات \\
\hline & $(r \cdot / \cdot) \Delta$ & $(q \cdot / \cdot))$ & 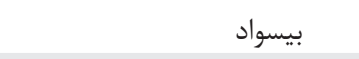 \\
\hline & $(\uparrow \varphi / \cdot \cdots) 9$ & $(r r / \cdots) \wedge$ & 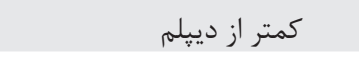 \\
\hline & $(F+\cdots) \| 1$ & $(T \Lambda / \cdot \cdot) V$ & تحصيلات دانشگاهى \\
\hline
\end{tabular}




\begin{tabular}{|ccc|}
\hline & & \\
\hline & \\
\hline
\end{tabular}

\begin{tabular}{|c|c|c|c|c|}
\hline \multicolumn{5}{|c|}{ جدول با: مقايسه ارتباط ميانگين ضرورت درمان در كروه مداخله و كنترل با فاكتورهاى دموكرافيك قبل از مداخله } \\
\hline P ارزش P & كروه مداخله، ميانگين 土 انحراف معيار & P ارزش P & كروه كنترل، ميانغين 土 انحراف معيار & متغير هاى دمو كرافيك \\
\hline \multirow[t]{3}{*}{$\cdot 109$} & & $\cdot|\Delta|$ & & جنسيت \\
\hline & $r / A r \pm 19$ & & $r / 1 \cdot \pm 19$ & 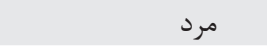 \\
\hline & $\varphi / 9 \varphi \pm|V| \Lambda \mid$ & & $r / \Delta \Lambda \pm I V / 4 \varphi$ & زن \\
\hline \multirow[t]{4}{*}{$\cdot / \cdot v$} & & $\cdot / r \Lambda$ & & تحصيلات \\
\hline & $T / T r \pm r \cdot / 9$. & & $F / \Delta \cdot \pm 1 N / V \Delta$ & 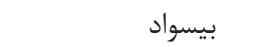 \\
\hline & $\Delta / \Delta V \pm I V$ & & $r / 19 \pm 19 / r \mu$ & زير ديبلم \\
\hline & ir & & $r / I r \pm I V$ & دانشَاهى \\
\hline \multirow[t]{3}{*}{$\cdot 190$} & & $\cdot / \mathrm{r}$ & & سن، سال \\
\hline & $\Delta / V T \pm I V / I F$ & & $r / V \Lambda \pm I V / \Lambda \Lambda$ & 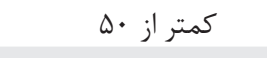 \\
\hline & $\mathrm{F} / \Delta V \pm 1 \Lambda / 99$ & & $r / V F \pm 19 / r r$ & بيش از • له \\
\hline
\end{tabular}

\begin{tabular}{|c|c|c|c|}
\hline \multicolumn{4}{|c|}{ جدول Fا: مقايسه ميانكين و انحر اف معيار نترانى از درمان دو كروه كنترل و مداخله قبل و بعد از مداخله } \\
\hline P ارزش P & كروه مداخله، ميانگين 土 انحراف معيار & كروه كنتر ل، ميانغين 土 انحراف معيار & ن تخرانى از درمان \\
\hline$\cdot / 4$ & $r / 99 \pm I V / r r$ & $r / 99 \pm 1 \wedge / 14$ & 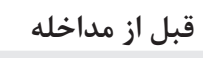 \\
\hline $.19 \mathrm{~V}$ & $r / 9 Q \pm \mid V / \cdot \Lambda$ & $r / q F \pm I V / F$. & بعد از مداخله \\
\hline & $\cdot 110$ & $\cdot / V V$ & P ارزش \\
\hline
\end{tabular}

جدول ه: مقايسه ارتباط ميانگين نمرات نغرانى از درمان در گروه مداخله و كنترل با فاكتورهاى دموَّرافيك قبل از مداخله

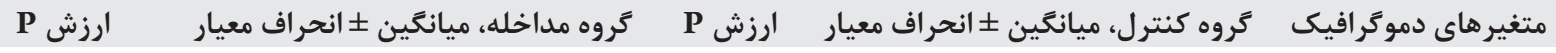
.191 . IVT

\begin{tabular}{|c|c|}
\hline$F / T F \pm 1$ IN/99 & $r / 9 V \pm I V / T$. \\
\hline$r / 4 q \pm 1 / / q \mu$ & $r / \cdot \varphi \pm I V / \varphi$ \\
\hline
\end{tabular}

$\cdot / l F$

\begin{tabular}{|c|c|c|c|}
\hline & $r / F T \pm 19 / 9$. & $r / 94 \pm 19$ & بيسواد \\
\hline & $r / \Delta 9 \pm 1 \wedge / V \wedge$ & $r / \Lambda 9 \pm 19 / 99$ & زير دييلم \\
\hline & it & $\Gamma / I \pm I V / \Delta$. & دانشعاهى \\
\hline & & & سال \\
\hline$/ \& \Delta$ & $r / \Delta r \pm 19 / V 1$ & $r / \Delta \Delta \pm I V / T V$ & كمتر از •ه \\
\hline & $r / V V \pm 1 N / \Delta$. & T/VE \pm IV/Tr & بيش از •ه \\
\hline
\end{tabular}

$\cdot 1 \wedge 9$ $r / I \pm I V / 0$. 


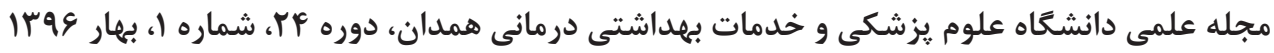

\begin{tabular}{|c|c|c|c|}
\hline \multicolumn{4}{|c|}{ جدول و: مقايسه ميانگين تغيير نمرات باور به درمان قبل و بعد از مداخله در هر دو گروه بيماران } \\
\hline P ارزش & كروه مداخله، ميانگين 土 انحراف معيار & كروه كنترل، ميانگين 土 انحراف معيار & 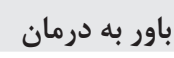 \\
\hline$\cdot \mid \Delta F$ & $r / \Lambda F \pm r / r F$ & $r / r q \pm r / \Lambda \Lambda$ & قبل از مداخله \\
\hline$\cdot 1 \cdot \cdot v$ & $r / G Y \pm r / \Delta T$ & $r / \uparrow \cdot \pm \Delta / \cdot r$ & 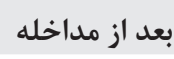 \\
\hline & $\cdot / k^{4}$ & $\cdot / 4 \mid$ & 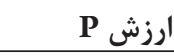 \\
\hline
\end{tabular}

\begin{tabular}{|c|c|c|c|c|}
\hline \multicolumn{5}{|c|}{ جدول V: مقايسه ارتباط ميانكين تغيير نمرات باور به درمان در گروه مداخله و كنترل با فاكتورهاى دموكرافيك قبل از مداخله } \\
\hline P ارزش & كروه مداخله، ميانغين 土 انحراف معيار & ارزش P & كروه كنترل، ميانكين 土 انحراف معيار & 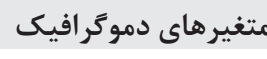 \\
\hline \multirow[t]{3}{*}{$\cdot 109$} & & (Tr & & جنسيت \\
\hline & $r / r \cdot \pm r / F r$ & & $r / \cdot q \pm 1 / \Lambda$. & مرد مرد \\
\hline & $r / F r \pm r / l r$ & & $r / 9 r \pm r / r$. & 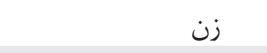 \\
\hline \multirow[t]{4}{*}{$\cdot / 14$} & & . IAT & & تحصيلات \\
\hline & $r / r \Delta \pm r / \Lambda$ & & $r / r \cdot \pm r / V \Delta$ & بيسواد \\
\hline & $r / G F \pm r / q r$ & & $r / \bullet \varphi \pm r / \cdot V$ & زير دييلم \\
\hline & - & & $r / 9 \cdot \pm r / V \Delta$ & دانشخاهى \\
\hline \multirow[t]{3}{*}{$\cdot /$ rᄉ } & & $\cdot|9|$ & & سن، سال \\
\hline & $r / q \gamma \pm r / \Lambda \Delta$ & & $r / l V \pm r / \cdot \varphi$ & كمتر از ••ه \\
\hline & $r / \cdot r \pm r / \omega$. & & $r / r q \pm r / \Delta \Delta$ & بيش از ••ه \\
\hline
\end{tabular}

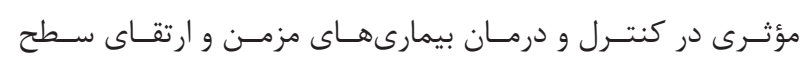

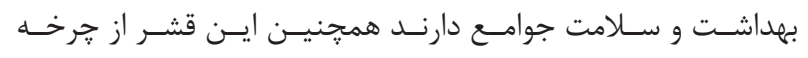

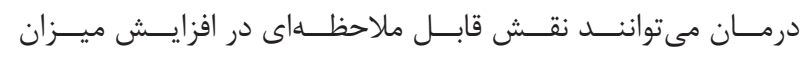

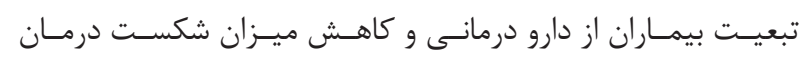

داشـته باشــند [1 إ]

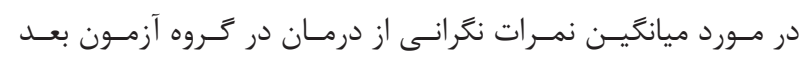

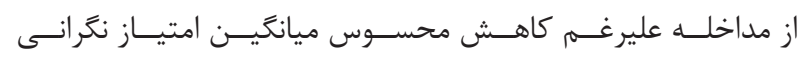

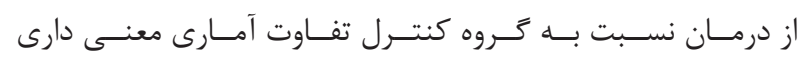

مشـاهده نشــد.

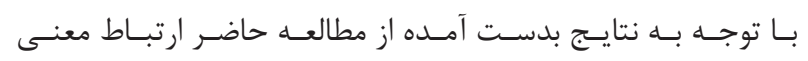

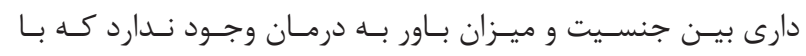

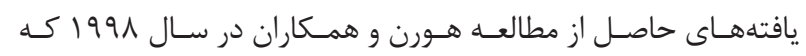

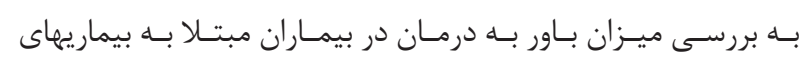

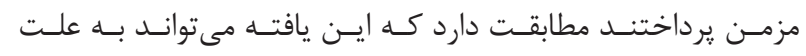

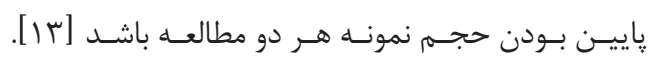

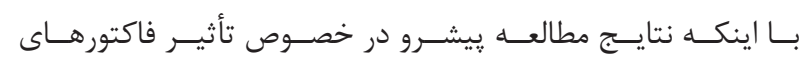

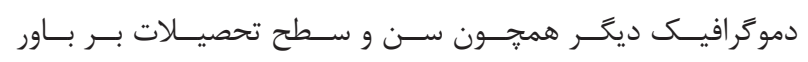

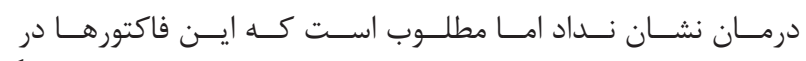

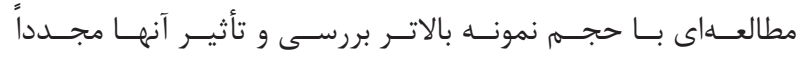
بــرآورد شــود.

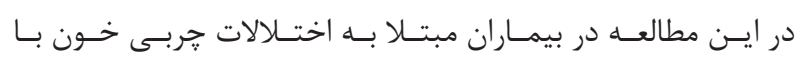

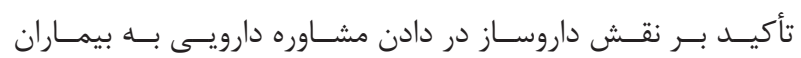

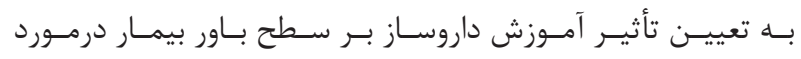

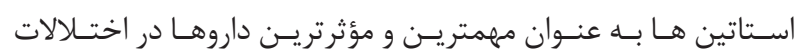

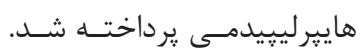

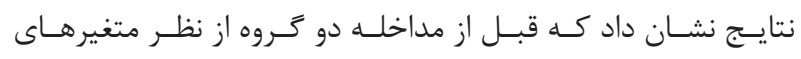

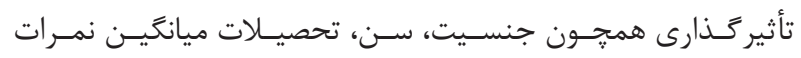

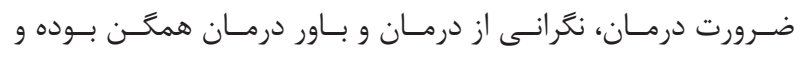

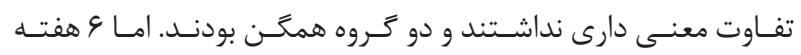

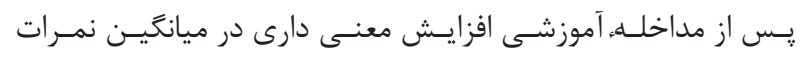

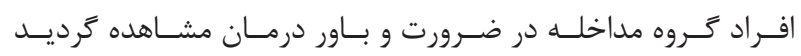

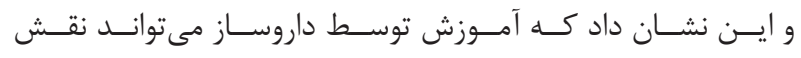

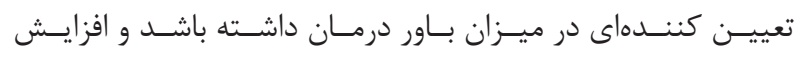

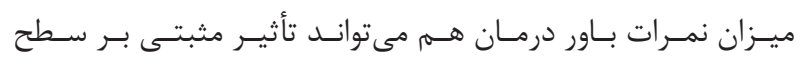

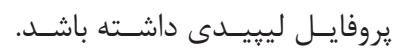

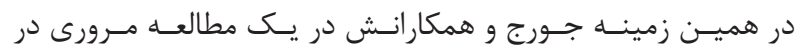

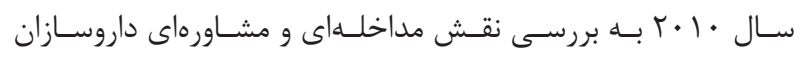

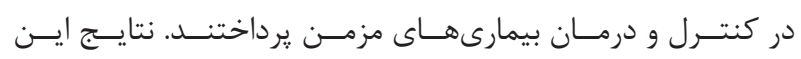

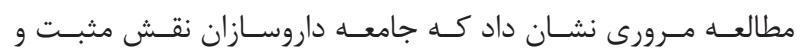


احتمــال شكسـت درمـان در ايـن افـراد دو برابـر بيمارانسى بـود كـهـ

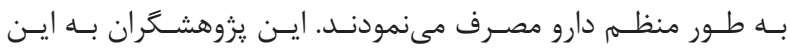

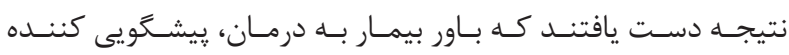

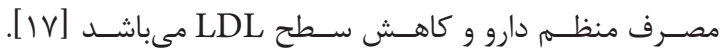

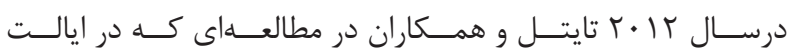

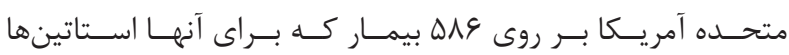

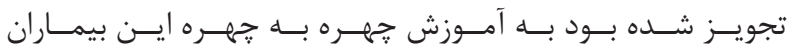

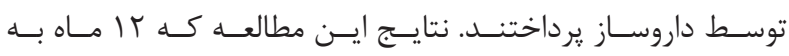

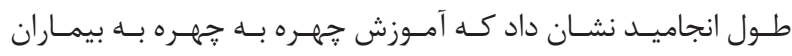

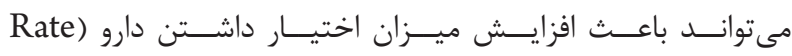
(Medication Possession

مناسـب دارو مىباشــد مىشــوند [1/].

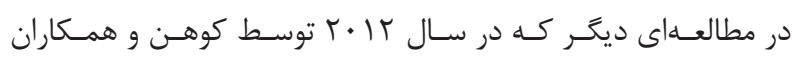

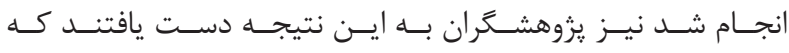

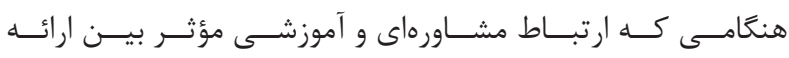

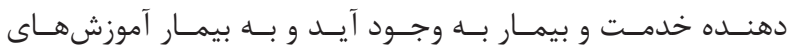

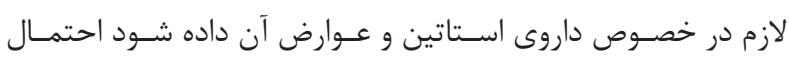

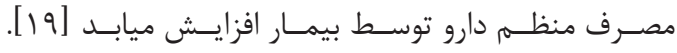

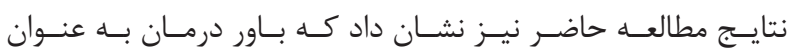

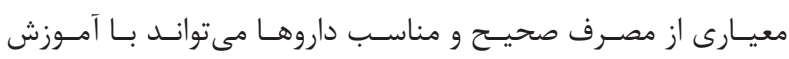

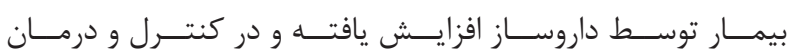

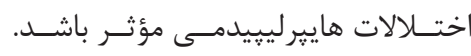

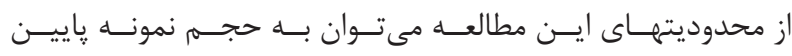

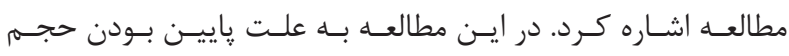

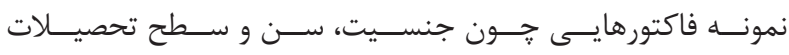

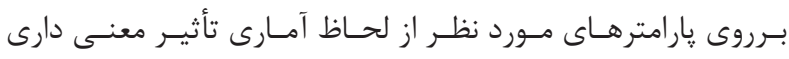

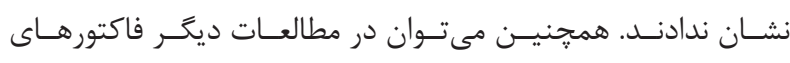

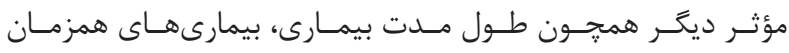

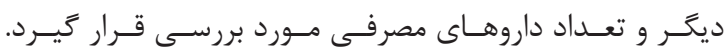

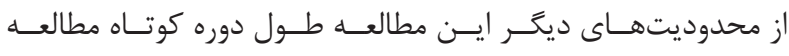

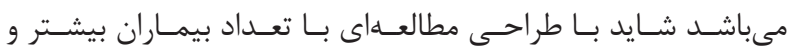

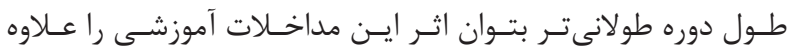

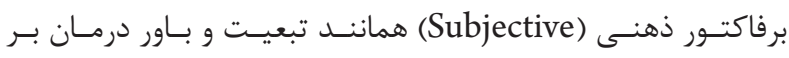

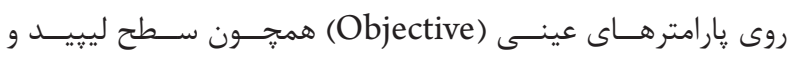

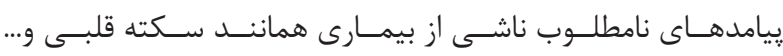
بررسـى نمــود.

\section{نتيجه تيرى}

آمـوزش توسـط افـراد متخصـص بالاخـص قشـــ داروسـاز در زمينــه

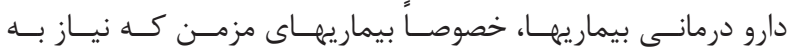

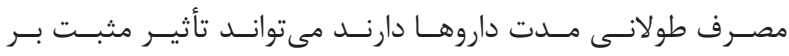

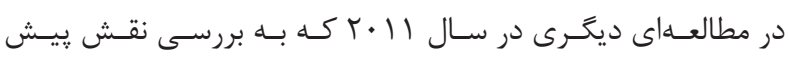

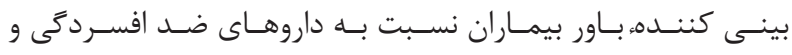

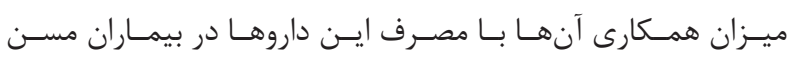

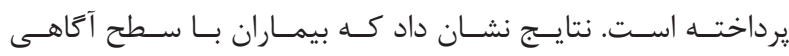

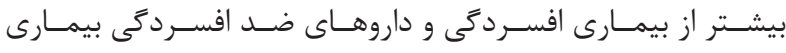

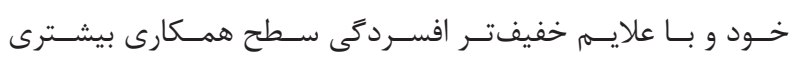

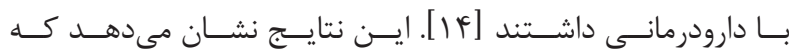

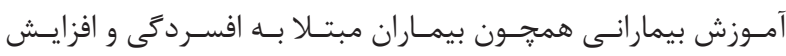

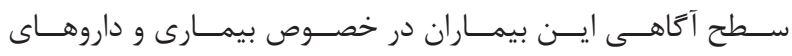

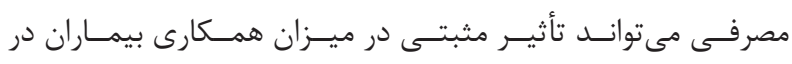

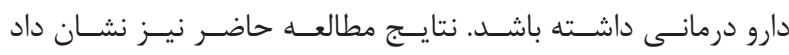

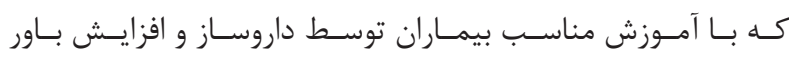

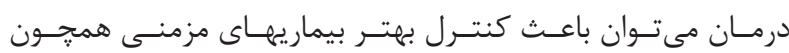

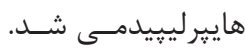
مطالعـات بسـيارى بـاور بيمـاران دربـاره داروهايشــان را بـهـ عنــــان

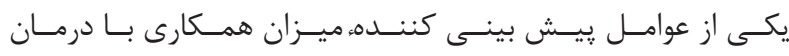

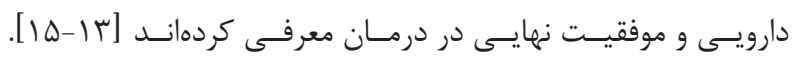

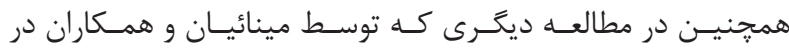

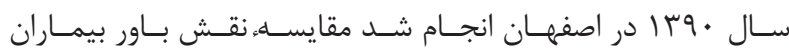

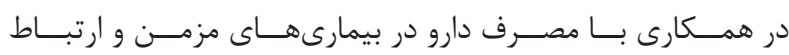

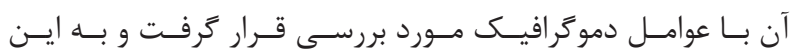

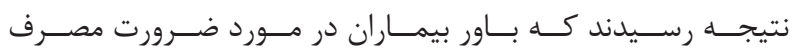

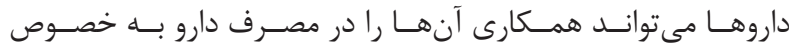

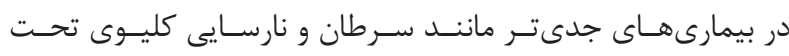

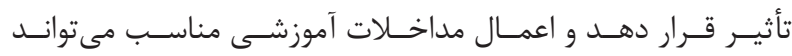

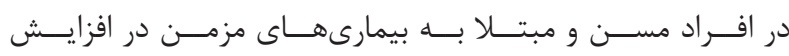

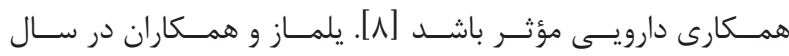

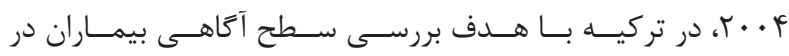

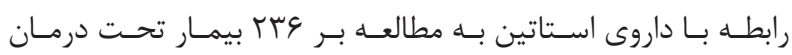

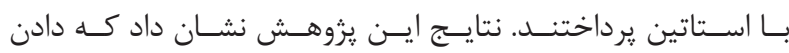

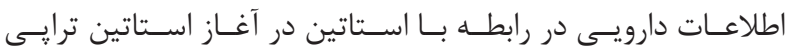

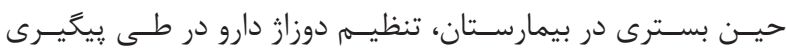

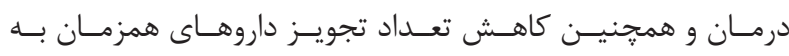

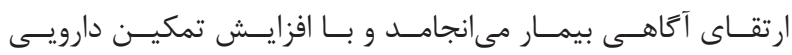

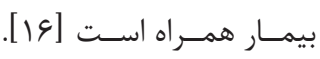

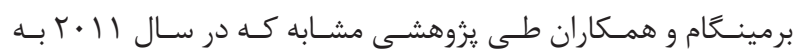

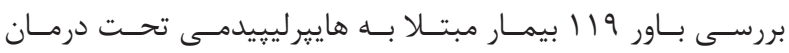

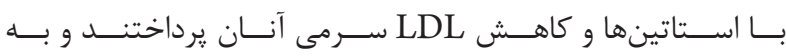

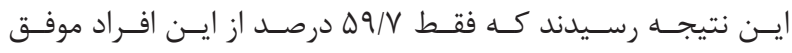

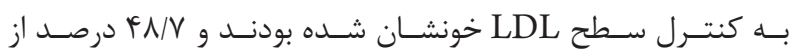

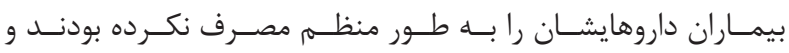




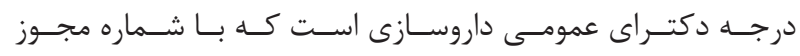

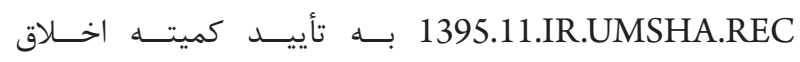

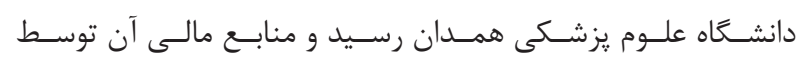

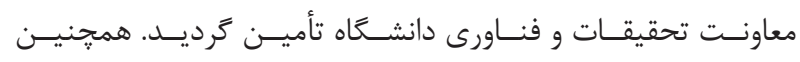

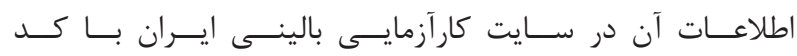

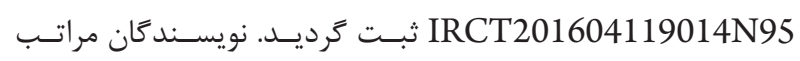

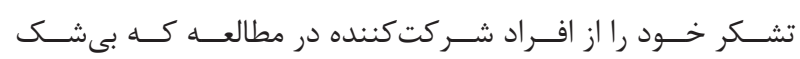

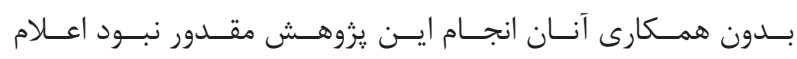

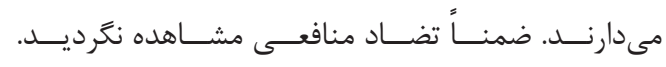

\section{REFERENCES}

1. Roger VL, Go AS, Lloyd-Jones DM, Adams RJ, Berry JD, Brown TM, et al. Heart disease and stroke statistics--2011 update: a report from the American Heart Association. Circulation. 2011;123(4):e18-e209. DOI: $10.1161 /$ CIR.0b013e3182009701 PMID: 21160056

2. Majdi M, Nikparast N, Bagherzadeh A, Puradine M, Saberi KM, Khani H. [The prevalence of hyperlipidemia and some effective factors in teachers of north khorasan province]. J North Khorasan Univ Med Sci. 2012;4(1):87.

3. Hernandez-Perera O, Perez-Sala D, Navarro-Antolin J, SanchezPascuala R, Hernandez G, Diaz C, et al. Effects of the 3-hydroxy-3-methylglutaryl-CoA reductase inhibitors, atorvastatin and simvastatin, on the expression of endothelin-1 and endothelial nitric oxide synthase in vascular endothelial cells. J Clin Invest. 1998;101(12):2711-9. DOI: 10.1172/JCI1500 PMID: 9637705

4. Pencina MJ, Navar-Boggan AM, D’Agostino RB, Sr., Williams K, Neely $\mathrm{B}$, Sniderman AD, et al. Application of new cholesterol guidelines to a population-based sample. N Engl J Med. 2014;370(15):1422-31. DOI: $10.1056 /$ NEJMoa1315665 PMID: 24645848

5. Grahame-Smith DG, Aronson JK. Oxford textbook of clinical pharmacology and drug therapy. UK: Oxford University Press; 1992.

6. Masror Roudsari DD, Dabiri Golchin M, Haghani H. Relationship between Adherence to Therapeutic Regimen and Health Related Quality of Life in Hypertensive Patients. Iran J Nurs. 2013;26(85):4454.

7. Sokol MC, McGuigan KA, Verbrugge RR, Epstein RS. Impact of medication adherence on hospitalization risk and healthcare cost. Med Care. 2005;43(6):521-30. PMID: 15908846

8. Minaiyan M, Taheri M, Mirmoghtadaee P, Marasi M. Comparative Role of Demographic Factors and Patient's Belief about Prescribed Medicine on Adherence to Drug Treatment in Chronic Diseases. J Isfahan Med Sch. 2011;29(156).

9. Hadi N, Rostami Gooran H, Jafary P. [Determinant factor of pts of shiraz, Iran]. Arch Iran Med. 2004;7(4):292-6.

10. Asadi Janati N, Vahdat S, Yazdan Panah A. Studying patient participation in controlling postoperative infection in orthognathic surgery in BouAli Hospital, Tehran in 2012-2013. Med Sci J Islam

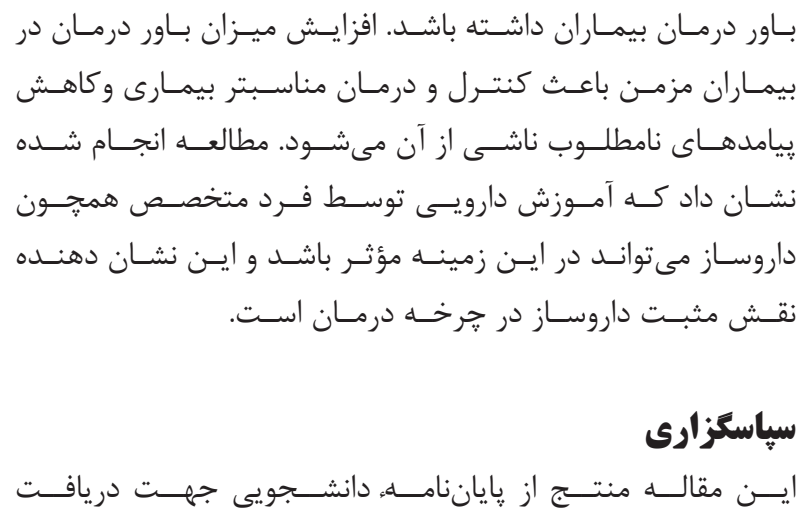

Azad Univ Tehran Med Branch. 2014;24(3):189-93.

11. Hallajian $\mathrm{H}$. [The pharmacist's consultation for chronic disorders]. Am J Hosp Pharm. 1987;35(6):704-8.

12. George PP, Molina JA, Cheah J, Chan SC, Lim BP. The evolving role of the community pharmacist in chronic disease management - a literature review. Ann Acad Med Singapore. 2010;39(11):861-7. PMID: 21165527

13. Horne R, Weinman J. Patients' beliefs about prescribed medicines and their role in adherence to treatment in chronic physical illness. J Psychosom Res. 1999;47(6):555-67. PMID: 10661603

14. Fawzi W, Abdel Mohsen MY, Hashem AH, Moussa S, Coker E, Wilson KC. Beliefs about medications predict adherence to antidepressants in older adults. Int Psychogeriatr. 2012;24(1):159-69. DOI: 10.1017/ S1041610211001049 PMID: 21729414

15. Gatti ME, Jacobson KL, Gazmararian JA, Schmotzer B, Kripalani S. Relationships between beliefs about medications and adherence. Am J Health Syst Pharm. 2009;66(7):657-64. DOI: 10.2146/ajhp080064 PMID: 19299373

16. Yilmaz MB, Biyikoglu SF, Guray Y, Karabal O, Caldir V, Cay S, et al. Level of awareness of on-treatment patients about prescribed statins. Cardiovasc Drugs Ther. 2004;18(5):399-404. DOI: 10.1007/ s10557-005-5065-9 PMID: 15717143

17. Bermingham M, Hayden J, Dawkins I, Miwa S, Gibson D, McDonald $\mathrm{K}$, et al. Prospective analysis of LDL-C goal achievement and self-reported medication adherence among statin users in primary care. Clin Ther. 2011;33(9):1180-9. DOI: 10.1016/j.clinthera.2011.07.007 PMID: 21840055

18. Taitel M, Jiang J, Rudkin K, Ewing S, Duncan I. The impact of pharmacist face-to-face counseling to improve medication adherence among patients initiating statin therapy. Patient Prefer Adherence. 2012;6:323-9. DOI: 10.2147/PPA.S29353 PMID: 22563240

19. Cohen JD, Brinton EA, Ito MK, Jacobson TA. Understanding Statin Use in America and Gaps in Patient Education (USAGE): an internet-based survey of 10,138 current and former statin users. J Clin Lipidol. 2012;6(3):208-15. DOI: 10.1016/i.jacl.2012.03.003 PMID: 22658145 
DOI: $10.21859 /$ hums-24019

Received: 22.10 .2016

Accepted: 15.04 .2017

Keywords:

Belief

Drugs-therapeutic use

Education

Hyperlipidemia

How to Cite this Article:

Mehrpooya M, Taravati Javad M, Larki A, Mohammadi Y, Ataei S, Kalvandi M. The Effect of Education by Pharmacists for Hyperlipidemic Patients Treated With Statins on Patient's Beliefs About Proper Use of Medications. Sci J Hamadan Univ Med Sci. 2017;24(1):63-71. DOI: $10.21859 /$ hums-24019

(C) 2017 Hamadan University of Medical Sciences.

\section{The Effect of Education by Pharmacists for Hyperlipidemic Patients Treated With Statins on Patient's Beliefs About Proper Use of Medications}

\author{
Maryam Mehrpooya ${ }^{1, *}$, Masoumeh Taravati Javad ${ }^{2}$, Amir Larki ${ }^{3}$, \\ Younes Mohammadi ${ }^{4}$, Sara Ataei ${ }^{1}$, Mitra Kalvandi ${ }^{5}$ \\ ${ }^{1}$ Assistant Professor, Department of Clinical Pharmacy, Faculty of Pharmacy, Ham- \\ adan University of Medical Sciences, Hamadan, Iran \\ ${ }^{2}$ MSc of Midwifery Consulting, Department of Midwifery, Faculty of Midwifery, \\ Hamadan University of Medical Sciences, Hamadan, Iran \\ ${ }^{3}$ Assistant Professor, Department of Pharmacologyw Toxicology, Faculty of Phar- \\ macy, Hamadan University of Medical Sciences, Hamadan, Iran \\ ${ }^{4}$ Assistant Professor, Department of Biostatistics, Faculty of Health, Hamadan \\ University of Medical Sciences, Hamadan, Iran \\ ${ }^{5}$ Pharm D, Department of Clinical Pharmacy, Faculty of Pharmacy, Hamadan \\ University of Medical Sciences, Hamadan, Iran \\ * Corresponding author: Maryam Mehrpooya, Assistant Professor, Department of \\ Clinical Pharmacy, Faculty of Pharmacy, Hamadan University of Medical Sciences, \\ Hamadan, Iran.E-mail: m.mehrpoya@umsha.ac.ir
}

\section{Abstract}

Introduction: Hyperlipidemia is one of the most common chronic diseases found in millions of people. Studies have shown that the patient's adherences to medication instructions provided by the pharmacist or doctor are important, yet unfortunately many patients do not adhere to proper usage of these drugs. The aim of this study was the evaluation of the effect of education by pharmacists for hyperlipidemic patients treated with statins on patient beliefs about the proper use of medications and compliance.

Methods: In this interventional clinical trial study, the studied population was all hospitalized patients with heart disease treated with statins at Hamadan Farshchian hospital from January 2016 to June 2016. The sample size in this study was 50. Information was obtained in relation to each patient, using 2 questionnaires including demographic characteristics and beliefs questionnaire. Data were analyzed using the SPSS.19 software and $t$ test, Mann-Whitney, and X2 tests. Significance level was considered less than 0.05 Results: Statistical test results showed that before the intervention, treatment belief was not significantly different between the 2 groups $(P=0.54)$, yet after the intervention the treatment belief increased in the intervention group $(P=0.007)$ and concern about using the drug declined.

Conclusion: These findings suggest that education by pharmacists in patients with hyperlipidemia could have a positive and effective role on their belief about the proper use of drugs. In other words, it could have a role in the control of chronic diseases and could help promote public health. 